\title{
Material Twisted/Bent
}

National Cancer Institute

\section{Source}

National Cancer Institute. Material Twisted/Bent. NCI Thesaurus. Code C62962.

Problem associated with deformations that lead to twisting or bending of the device. 